\title{
Evaluation of axonal loss in ulnar sensory nerve fibers recorded from ring and little fingers secondary to idiopathic carpal tunnel syndrome in Egyptian patients
}

\author{
Aliaa Omar El-Hady ${ }^{1}$, Soad Said Ahmed El Molla ${ }^{2}$ and Rehab Ali Ibrahim³
}

\begin{abstract}
Background: The association between carpal tunnel syndrome (CTS) and ulnar nerve entrapment is unclear, and the extra-median paresthesia in the ulnar nerve territory innervation in CTS is unexplained. Our purpose is to evaluate the neurophysiologic changes in ulnar nerve sensory fibers secondary to idiopathic CTS in comparison to normal subjects, and their relation to the severity of CTS.

Results: The difference between CTS and control hands regarding all parameters of ulnar motor nerve conduction studies (MNCS) was not statistically significant $(p>0.05)$. There was a statistically significant difference in all parameters of median sensory conduction study (SCS) and MNCS between CTS and control hands $(p<0.0001)$ except for conduction velocity and in all parameters of median and ulnar SCS recording digit 4 (D4) $(p<0.05)$. The mean value of abnormalities of ulnar SCS recording D4 and digit 5 (D5) was significantly higher in moderate and severe CTS hands $(p<0.05)$. There were significant negative correlations between median motor and sensory latency and ulnar sensory amplitude recording D4 and D5.

Conclusion: Ulnar sensory nerve abnormalities exist among CTS patients, which were more in moderate and severe grades. The drop in amplitude of ulnar nerve sensory response argues in favor of the possible impact of CTS on the ulnar nerve and did not indicate axonal deterioration of the ulnar nerve.
\end{abstract}

Keywords: Carpal tunnel syndrome, Median versus ulnar comparative studies, Motor conduction, Sensory conduction, Extra-median paresthesia, Axonal loss

\section{Background}

Carpal tunnel syndrome (CTS) is the commonest type of nerve entrapment syndromes causing significant socioeconomic costs [1].

Guyon's canal (GC) syndrome is an uncommon peripheral neuropathy where the ulnar nerve is entrapped through the narrow canal at the wrist [2]. Many studies analyzed the possible ulnar nerve affection at the region of the wrist in CTS [1], which mainly involved sensory fibers,

\footnotetext{
*Correspondence: rehab_ali_i@hotmail.com; dr.rehabali@med.asu.edu.eg ${ }^{3}$ Physical Medicine, Rheumatology and Rehabilitation Department, Faculty of Medicine, Ain Shams University, Cairo, Egypt

Full list of author information is available at the end of the article
}

and that ulnar nerve conduction abnormality was augmented with the increase in the severity of CTS [3-13].

Studies suggested that a sensory change in the ulnar nerve in CTS is functional rather than mechanical. Increased pressure in the CTS causes a mechanical traction on the transverse carpal ligament increasing GC pressure resulting in functional changes in the ulnar nerve, and decompression surgery for CTS resulted in the relief of the GC pressure with spontaneous reduction in the symptoms regarding the ulnar nerve [6, 14-17].

This study aimed to evaluate ulnar nerve sensory fibers' neurophysiologic changes secondary to idiopathic 
CTS in comparison to normal subjects, and their relation to CTS severity.

\section{Methods}

A prospective case-control cross-sectional study included 183 hands from 100 patients clinically diagnosed as idiopathic CTS. They were recruited from the neurophysiology clinics of physical medicine and rehabilitation departments of Mataria teaching hospital and Ain Shams university hospitals. CTS diagnosis was based on the presence of one or more of the following clinical symptoms including numbness, tingling or paresthesia in the distribution of the median nerve, sensory manifestations causing nocturnal awakening, symptoms that are triggered by hand activity and relived with hand elevation or shaking, and the presence of positive Tinel's or Phalen sign [18]. Ninety-two asymptomatic hands recruited from 50 age- and sex-matched apparently healthy subjects were selected as a control group. Patients with systemic diseases, neurological diseases (such as radiculopathy, plexopathy, thoracic outlet syndrome, and myelopathy), pregnancy, metabolic or endocrine diseases, previous CTS decompression operation, and ulnar nerve entrapment at any level electrophysiologically diagnosed were excluded from the study. The study was described to the studied subjects, and an informed consent was given by all.

CTS patients were evaluated clinically by history and full neurological examination, emphasizing on the occurrence of sensory complaint in the territory of the median nerve and/or extra-median distribution of symptoms.

Electrophysiological studies were conducted to all studied subjects using Dantek "Keypoint" electromyography 2 channels measuring nerve conduction/ EMG/evoked potentials system (DANTEK, Skorlunde, Denmark) and using Nihon Kohden Neuropack with a two-channel evoked potential/EMG measuring system (Nihon Kohden Corporation, Tokyo, Japan).

Nerve conduction study techniques of median and ulnar nerves and their recording protocol were performed to all subjects in the study according to Preston and Shapiro [19]. The study included the following:

- Motor nerve conduction study of the median nerve recording abductor pollicis brevis muscle

- Motor nerve conduction study of the ulnar nerve recording abductor digiti minimi muscle

- Sensory nerve conduction study of the median nerve [recording digit 2 (D2)]

- Sensory nerve conduction study of the ulnar nerve [recording digit 5 (D5)]

- Median versus ulnar SCS [recording digit 4 (D4)]
Patients were subdivided into electrophysiological subgroups according to the Bland scale for severity grading of CTS [20]. According to the Bland scale for simplification, our patients were grouped as minimal (grade 1), mild (grade 2), moderate (grades 3 and 4), and severe (grade 5). Grade 6 was not included in the study.

\section{Ethics approval and consent to participate}

This study was conducted after the approval of the ethics committee of the General Organization for Teaching Hospitals and Institutes (GOTHI), with reference number HM00122. All patients in this study gave written informed consent to participate in this research.

\section{Statistical analysis}

All tabulated data were statistically analyzed by using the IBM SPSS, New York, USA, version 25 software. Descriptive measures (minimum, maximum, mean, and SD) and analytic comparison measures (independent Student $t$ test between means, one-way ANOVA in between groups, in addition to Pearson chi-square test) were used. Correlation studies were done using the Pearson regression equation, and statistical significance was measured to $p$ value $\leq 0.05$.

\section{Results}

The current study included 183 idiopathic CTS clinically diagnosed that were collected from 100 patients [89 women $(89 \%)$ and 11 men (11\%)]. Their mean age was $40.86 \pm 11.6$ years (ranged from 18 to 75 years). The control group included 92 hands that were collected from 50 healthy subjects [ 42 women $(84 \%)$ and 8 men (16\%)]. Their mean age was $38.17 \pm 12.5$ years (ranged from 18 to 66 years). No statistically significant differences were found between patients and the control group as regards age $(t=1.766, p=0.082)$ and sex $\left(\chi^{2}=\right.$ $0.868, p=0.386)$. The clinical parameters of patient and control groups are summarized in Table 1.

In the CTS group, $51.37 \%$ of cases confined paresthesia to the sensory zone of the median nerve and in $48.63 \%$ in extra-median sensory territory (whole hand or ulnar sensory territory, i.e., little finger or ring and little fingers only).

According to electrophysiological severity, 87 hands (47.54\%) had minimal CTS, 43 hands (23.5\%) had mild CTS, 41 hands (22.4\%) had moderate CTS, and 12 hands (6.56\%) had severe CTS. There was no statistical significance difference between patients with different CTS electrophysiological severity grades and control group as regards sex $(F=0.353, p=0.842)$ and age $(F=2.151, p=0.075)$.

The results of the NCSs of the studied nerves are shown in Table 2. There was a statistically significant 
Table 1 Clinical characteristics of patient and control groups

\begin{tabular}{|c|c|c|c|c|}
\hline Clinical data & CTS group (183 hands from 100 patients) & Control group (92 hands from 50 healthy subjects) & $t$ & $p$ \\
\hline Women (no. and \%) & 89 (89\%) & $42(84 \%)$ & 0.868 & 0.386 \\
\hline Men (no and \%) & $11(11 \%)$ & & & \\
\hline Age (years) mean $\pm S D$ & $40.86 \pm 11.6$ & $38.17 \pm 12.5$ & 1.766 & 0.082 \\
\hline Bilateral/unilateral & $83(83 \%) / 17(17 \%)$ & $42(84 \%) / 8(16 \%)$ & 0.210 & 0.834 \\
\hline Side (right/left) & $95(51.9 \%) / 88(48.1 \%)$ & $47(51.8 \%) / 45(48.9 \%)$ & 0.016 & 0.987 \\
\hline Median/extra-median symptoms & $94(51.37 \%) / 89(48.63 \%)$ & NA & NA & NA \\
\hline
\end{tabular}

CTS carpal tunnel syndrome, SD standard deviations, NA not applicable

difference between CTS patients and control regarding all the studied parameters $(p<0.05)$ except for median and ulnar nerve motor conduction velocities which were lower than the control but did not reach statistical significance. There were no statistically significant differences between patients and the control group as regards all parameters of ulnar motor conduction study $(p>$ 0.05). As regards the difference in ulnar nerve sensory studies recording D4 between CTS patients and control subjects, there were prolonged peak latency, lower amplitude, and slow conduction velocity with a statistically significant difference as $p<0.05$.

The comparison of ulnar NCS parameters between patients with different CTS electrophysiological severity grades and control subjects is shown in Table 3.

There were no statistically significant differences between different CTS electrophysiological severity grades and the control group as regards all parameters of ulnar nerve motor conduction studies. There were statistically significant differences in all parameters of ulnar SCS

Table 2 Comparison of nerve conduction study parameters between case and control groups

\begin{tabular}{|c|c|c|c|c|}
\hline NCS parameters & Patients ( $n=183$ hands) & Control ( $n=92$ hands) & $t$ & $p$ \\
\hline \multicolumn{5}{|l|}{ Median motor } \\
\hline MM DL & $4.07 \pm 1.3$ & $3.24 \pm 0.4$ & 5.986 & $<0.0001^{*}$ \\
\hline MM amp & $8.04 \pm 2.8$ & $9.4 \pm 2.5$ & -3.946 & $<0.0001^{*}$ \\
\hline MM CV & $56.8 \pm 6.3$ & $58.43 \pm 5.4$ & -1.543 & 0.124 \\
\hline \multicolumn{5}{|c|}{ Median sensory D2 } \\
\hline MS PL & $3.79 \pm 1.05$ & $2.87 \pm 0.3$ & 5.207 & $<0.0001^{*}$ \\
\hline MS amp & $33.7 \pm 19.8$ & $48.8 \pm 15.1$ & -4.840 & $<0.0001^{*}$ \\
\hline MS CV & $47.35 \pm 11.5$ & $59.7 \pm 6.05$ & -9.710 & $<0.0001^{*}$ \\
\hline \multicolumn{5}{|l|}{ Ulnar motor } \\
\hline UM DL & $2.53 \pm 0.4$ & $2.43 \pm 0.4$ & 1.817 & 0.070 \\
\hline UM amp & $9.11 \pm 2.7$ & $9.22 \pm 1.9$ & -0.343 & 0.732 \\
\hline UM CV & $61.27 \pm 2.5$ & $62.5 \pm 5.3$ & -1.788 & 0.075 \\
\hline \multicolumn{5}{|c|}{ Ulnar sensory D5 } \\
\hline US PL & $2.52 \pm 0.3$ & $2.44 \pm 0.25$ & 2.230 & $0.027^{*}$ \\
\hline US amp & $26.33 \pm 16.4$ & $35.23 \pm 19.1$ & -4.014 & $<0.0001^{*}$ \\
\hline US CV & $57.7 \pm 6.7$ & $61.2 \pm 5.7$ & -4.291 & $<0.0001^{*}$ \\
\hline \multicolumn{5}{|c|}{ Median vs. ulnar D4 } \\
\hline ML4 & $3.81 \pm 1.15$ & $2.72 \pm 0.38$ & 8.865 & $<0.0001^{*}$ \\
\hline Mamp4 & $20 \pm 12.3$ & $31.62 \pm 13.8$ & -7.095 & $<0.0001^{*}$ \\
\hline MCV4 & $44.2 \pm 12.5$ & $58.7 \pm 7.2$ & -10.238 & $<0.0001^{*}$ \\
\hline UL4 & $2.73 \pm 0.4$ & $2.57 \pm 0.3$ & 3.429 & $0.001^{*}$ \\
\hline Uamp4 & $18.52 \pm 12.86$ & $23.06 \pm 14.2$ & -4.042 & $<0.0001^{*}$ \\
\hline UCV4 & $58.16 \pm 8.4$ & $62.3 \pm 6.76$ & -4.146 & $<0.0001^{*}$ \\
\hline
\end{tabular}

$D L$ distal latency, amp amplitude, $C V$ conduction velocity, $M M$ median motor, $M S$ median sensory, $P L$ peak latency, $D 5$ digit five recording, $D 4$ digit four recording, ML4 median latency recorded from 4th digit, Mamp4 median amplitude recorded from 4th digit, MCV4 median conduction velocity recorded from 4th digit, UL4 ulnar latency recorded from 4th digit, Uamp4 ulnar amplitude recorded from 4th digit, UCV4 ulnar conduction velocity recorded from 4th digit ${ }^{*} p$ is significant at $\leq 0.05$ 
Table 3 Comparison of different ulnar nerve conduction study parameters between patients with different CTS electrophysiological severity grades and control subjects

\begin{tabular}{|c|c|c|c|c|c|c|c|c|c|c|}
\hline & \multirow{2}{*}{$\begin{array}{l}\text { Control (92) } \\
\text { Mean } \pm \text { SD }\end{array}$} & \multirow{2}{*}{$\begin{array}{l}\text { Minimal CTS (87) } \\
\text { Mean } \pm \text { SD }\end{array}$} & \multirow{2}{*}{$\begin{array}{l}\text { Mild CTS (43) } \\
\text { Mean } \pm \text { SD }\end{array}$} & \multirow{2}{*}{$\begin{array}{l}\text { Moderate CTS (41) } \\
\text { Mean } \pm \text { SD }\end{array}$} & \multirow{2}{*}{$\begin{array}{l}\text { Severe CTS(12) } \\
\text { Mean } \pm S D\end{array}$} & \multirow{2}{*}{$\begin{array}{l}p, \\
\text { between } \\
\text { all groups }\end{array}$} & \multirow{2}{*}{$\begin{array}{l}p_{1} \\
\text { control } \\
\text { and } \\
\text { minimal }\end{array}$} & \multirow{2}{*}{$\begin{array}{l}p, \\
\text { control } \\
\text { and } \\
\text { mild }\end{array}$} & \multirow{2}{*}{$\begin{array}{l}p, \text { control } \\
\text { and } \\
\text { moderate }\end{array}$} & \multirow{2}{*}{$\begin{array}{l}p, \\
\text { control } \\
\text { and } \\
\text { severe }\end{array}$} \\
\hline & & & & & & & & & & \\
\hline$\overline{\mathrm{UM} \mathrm{DL}}$ & $2.43 \pm 0.4$ & $2.39 \pm 0.3$ & $2.5 \pm 0.4$ & $2.57 \pm 0.41$ & $2.42 \pm 0.43$ & 0.133 & 0.605 & 0.321 & 0.071 & 0.950 \\
\hline UM amp & $9.22 \pm 1.9$ & $9.16 \pm 3.2$ & $9.15 \pm 2.4$ & $8.96 \pm 1.6$ & $8.97 \pm 1.5$ & 0.983 & 0.879 & 0.855 & 0.446 & 0.671 \\
\hline UM CV & $62.5 \pm 5.3$ & $62.09 \pm 5.4$ & $61.6 \pm 4.5$ & $60.8 \pm 5.5$ & $59.8 \pm 8$ & 0.299 & 0.603 & 0.337 & 0.088 & 0.123 \\
\hline US PL & $2.44 \pm 0.25$ & $2.4 \pm 0.3$ & $2.5 \pm 0.4$ & $2.56 \pm 0.3$ & $2.6 \pm 0.3$ & $0.022^{*}$ & 0.980 & 0.269 & $0.018^{*}$ & $0.044^{*}$ \\
\hline US amp & $35.23 \pm 19.1$ & $30.33 \pm 15.4$ & $29.1 \pm 19.2$ & $25.5 \pm 11.65$ & $22.58 \pm 17.3$ & $0.010^{*}$ & 0.061 & 0.084 & $0.003^{*}$ & $0.032^{*}$ \\
\hline US CV & $61.2 \pm 5.7$ & $59.86 \pm 5.7$ & $57.5 \pm 7.3$ & $55.74 \pm 5.5$ & $55.78 \pm 7.1$ & $<0.0001^{*}$ & 0.122 & $0.002^{*}$ & $<0.0001^{*}$ & $0.003^{*}$ \\
\hline UL4 & $2.57 \pm 0.3$ & $2.59 \pm 0.3$ & $2.71 \pm 0.44$ & $2.85 \pm 0.34$ & $2.76 \pm 0.4$ & $<0.0001^{*}$ & 0.781 & $0.038^{*}$ & $<0.0001^{*}$ & $0.007^{*}$ \\
\hline Uamp4 & $23.06 \pm 14.2$ & $20.6 \pm 10.2$ & $17.9 \pm 13$ & $17.4 \pm 11.6$ & $16.7 \pm 5$ & $0.047^{*}$ & 0.187 & $0.046^{*}$ & $0.027^{*}$ & 0.129 \\
\hline UCV4 & $62.3 \pm 6.76$ & $60.56 \pm 7.2$ & $57.2 \pm 10.6$ & $57.78 \pm 8.34$ & $56.3 \pm 6$ & $0.0007^{*}$ & 0.097 & $0.001^{*}$ & $0.001^{*}$ & $0.004^{*}$ \\
\hline
\end{tabular}

UM ulnar motor, $D L$ distal latency, amp amplitude, CV conduction velocity, US ulnar sensory, PL peak latency, UL4 ulnar latency recorded from 4th digit, Uamp4 ulnar amplitude recorded from 4th digit, UCV4 ulnar conduction velocity recorded from 4th digit

${ }^{*} p$ is significant at $\leq 0.05$

recording D4 and D5 between CTS severity groups and the control group in which there were prolongation in latency $(F=2.9, p=0.022$ and $F=6.299, p=0.0001$ respectively), reduction in amplitude $(F=3.39, p=0.01$ and $F=2.45, p=0.047$ respectively), and delay conduction velocity $(F=8.03, p<0.0001$ and $F=4.44, p=$ 0.0007 respectively).

The mean value of abnormality of ulnar sensory parameters recording D4 and D5 was significantly higher in hands with CTS severity in moderate and severe grades than in minimal CTS as shown in Table 3. Correlation study between different parameters of ulnar sensory NCSs and parameters of median motor conduction studies and sensory PL are shown in Table 4.

There was a statistically significant negative correlation between median motor distal latency (DL) and ulnar sensory amplitude recording D5 and D4 $\left(r=-0.373^{* *}, p \leq 0.0001\right.$ and $r=-0.154^{*}, p=$ 0.037 respectively). There was a statistically significant negative correlation between median sensory $\mathrm{PL}$ and ulnar sensory amplitude recording D5 and D4 $\left(r=-0.379^{* * *}, p \leq 0.0001\right.$ and $r=-0.174^{*}$, $p=0.018$ respectively). There was a statistically significant positive correlation between median motor DL and ulnar sensory PL recording D4 $\left(r=0.147^{*}\right.$, $p=0.049)$.

There was a statistically significant positive correlation between median sensory PL and ulnar sensory PL recording D5 and D4 ( $r=0.187^{*}, p=0.011$ and $r$ $=0.270^{* * *}, p \leq 0.0001$ respectively).

\section{Discussion}

CTS diagnosis is assessed by clinical studies integrating NCSs. The CTS symptoms are mainly sensory in the region of median nerve innervation and median nerve abnormal SCS with or without motor abnormality associated with normal ipsilateral ulnar conduction. $\mathrm{Nu}$ merous CTS patients had extra-median spread of

Table 4 Correlation between median motor distal latency and sensory peak latency and conduction studies of ulnar nerve recording D4 and D5

\begin{tabular}{|c|c|c|c|c|c|c|c|c|}
\hline \multirow{2}{*}{$\begin{array}{l}\text { Nerve } \\
\text { conduction } \\
\text { study } \\
\text { parameters }\end{array}$} & \multicolumn{2}{|c|}{ Median motor DL } & \multicolumn{2}{|c|}{ Median motor amp } & \multicolumn{2}{|c|}{ Median motor CV } & \multicolumn{2}{|c|}{ Median sensory PL } \\
\hline & $r$ & $p$ & $r$ & $p$ & $r$ & $p$ & $r$ & $p$ \\
\hline US PL & 0.115 & 0.123 & 0.093 & 0.212 & $-0.214^{* *}$ & 0.004 & $0.187^{*}$ & 0.011 \\
\hline US amp & $-0.373^{* *}$ & $<0.0001$ & $0.211^{* *}$ & 0.004 & 0.016 & 0.825 & $-0.379^{* *}$ & $<0.0001$ \\
\hline US CV & -0.119 & 0.108 & 0.082 & 0.271 & 0.299 & $<0.0001$ & -0.170 & 0.021 \\
\hline UL4 & $0.147^{*}$ & 0.049 & 0.033 & 0.655 & $-0.299^{* *}$ & $<0.0001$ & $0.270^{* *}$ & $<0.0001$ \\
\hline Uamp4 & $-0.154^{*}$ & 0.037 & -0.006 & 0.940 & $-0.171^{*}$ & 0.021 & $-0.174^{*}$ & 0.018 \\
\hline UCV4 & 0.032 & 0.670 & 0.244 & 0.238 & $0.238^{* *}$ & 0.001 & -0.048 & 0.522 \\
\hline
\end{tabular}

D4 digit 4, D5 digit 5, amp amplitude, CV conduction velocity, US ulnar sensory, PL peak latency, UL4 ulnar latency recorded from 4th digit, Uamp4 ulnar amplitude recorded from 4th digit, UCV4 ulnar conduction velocity recorded from 4th digit, $r$ Pearson correlation coefficient

${ }^{*} p$ is significant at $\leq 0.05,{ }^{* *}<0.01$ highly significant 
paresthesia including the zone of innervation of the ulnar nerve. Motor and sensory median versus ulnar nerve comparative conduction studies were utilized in the diagnosis of early CTS, and if there were any changes in ulnar sensory and motor NCS in these patients suffering CTS, this might alter the accuracy of these tests. The aim of the study was to evaluate the neurophysiologic changes in sensory fibers of ulnar nerve secondary to idiopathic CTS in comparison to normal subjects, and their relation to the severity of CTS.

Earlier electrophysiological studies have shown that traction of nearby ulnar nerve fibers may occur in patients with CTS $[3,5,7,8,12,17]$. In addition, in an old retrospective study involving the results of 234 cases with CTS, Sedal et al. [3] reported that sensory nerve action potential amplitude of ulnar nerve was found to be abnormal in $39.3 \%$ of their CTS cases which was associated with increased sensory latency and reduced sensory amplitude of the ulnar nerve. There was also a significant correlation between the amplitudes of median and ulnar sensory nerve action potentials and a significant correlation between the median nerve motor conduction velocity and the ulnar nerve sensory action potential amplitude, and the abnormality in SCS regarding the ulnar nerve was related to delay in the median nerve motor conduction velocity at the forearm, suggesting that other factors outside the carpal tunnel might be significant in the pathogenesis of the disorder and supporting the idea of a hidden widespread subclinical neuropathy that might occur in some patients with CTS. Gozke et al. [5] performed nerve conduction studies (NCSs) in 65 hands of 53 CTS patients and described that $18.4 \%$ had ulnar nerve entrapment at the level of the wrist to some extent and the abnormalities were found only among the ulnar sensory fibers with no abnormalities among the ulnar motor fibers. They also stated that impairment of the ulnar nerve was found mostly in CTS patients with moderate and severe degrees with no impairment in those with very mild degree of CTS. There was no control group for those two studies $[3,5]$. In another study with a larger number of patients, Ginanneschi et al. revealed that ulnar sensory amplitudes recording D4 and D5 were significantly decreased in patients with CTS than in the control group and the ulnar motor DL was not significantly different than control. They reported the occurrence of significant alterations in ulnar NCS yet in the mild phases of CTS. There was a significantly positive correlation between CTS severity and ulnar SCS abnormalities. They speculated that the pressure in the CT increases with the increased severity of CTS leading to compression force transmission to GC causing ulnar NCS abnormalities [17]. Cassvan et al. [4] stated that entrapment of the ulnar nerve at the wrist was observed in $46 \%$ of the patients. There were $15 \%$ of their studied CTS hands in whom ulnar motor NCSs showed abnormalities. They found that ulnar nerve abnormalities frequently occurred among patients with cervical radiculopathy. Patients with cervical radiculopathy were not included in the current study.

The current study showed ulnar sensory nerve fiber affection. The ulnar sensory nerve amplitudes recording D4 and D5 were significantly lower among CTS hands versus controls. The ulnar sensory parameters recording D5 and D4 were significantly affected (slow amplitude, delay peak latency, and conduction velocity) among moderate and severe CTS than the controls and hands with minimal CTS.

The present study showed statistically significant negative correlations between both ulnar sensory amplitude recording D5 and D4 and median DL as well as positive correlations between both ulnar sensory amplitude recording D5 and D4 and median sensory PL. These significant correlations suggested that various ulnar sensory fibers were equally involved with more progression of median nerve compression at the wrist.

This study did not identify any ulnar motor fiber involvement among CTS patients compared to the control group. This might be due to minimal impairment within the motor fibers of the ulnar nerve which could not be identified by applying standard electrophysiological techniques [21]. Additionally, this could be explained by distinct properties of the sensory and motor fibers of the ulnar nerve, making the sensory fibers more vulnerable to be compressed $[17,22]$.

Some previous investigations clarified that affection of ulnar nerve sensory fibers in CTS patients is probably due to its traction by forces of compression transferred to GC by high pressure in the carpal tunnel causing an incidental compression of ulnar nerve fibers especially the distal portion which is more susceptible to external compression or due to association of ulnar neuropathy with CTS $[14,15,21,23]$.

The current study was in agreement with an Egyptian study done by Saba and El-Tawab [24]; they studied the parameters of ulnar nerve SCS in 145 CTS hands from 102 patients in a case-control study with 71 asymptomatic hands and reported that there was ulnar sensory nerve variation from the normal in CTS documented by decreased ulnar sensory nerve action potential amplitude without any changes in the sensory conduction. The ulnar MNCS were normal. Additionally, they stated that abnormalities in ulnar nerve happen in moderate and severe CTS.

This study did not support the results of Moghtaderi and Ghafarpoor [25]. They revealed that the correlation regarding ulnar nerve conduction abnormality between 
CTS patients and the control group in their case-control study with 99 healthy volunteers and 181 patients (absolutely 378 hands) was not statistically significant. Tamburin et al. [26] additionally examined NCS parameters of the ulnar nerve in 143 CTS patients (225 hands) and detailed that ulnar sensory variations from the normal did not participate in the propagation of sensory symptoms to the ulnar zone. Azmy et al. [8] detailed that the differences in the peak latency of ulnar sensory or their conduction velocities recorded from 4th and 5th fingers between CTS patients and the control group were not statistically significant. Moreover, previous reports introduced some evidences that patients with extra-median sensory manifestations have an augmented hand representation in the sensory cortex which might support the likelihood of a central mechanism as opposed to an ulnar neuropathy in CTS as a cause of extra-median sensory manifestations [27-29].

In their comprehensive systematic review, Ginanneschi et al. [1] stated that CTS could determine an effect on GC morphology as well as on the morphology and function of the ulnar nerve at the wrist. Literature analysis of the relationship between CTS frequency and ulnar nerve conduction defects made it clear that the main causative factor might be compressive forces transmitted from the carpal tunnel to Guyon's canal as a result of high pressure in the carpal tunnel. The most prominent influence was on the sensory conduction [1]. We suggest that impaired neurodynamics in CTS might be one of the mechanisms for such clinical and neurophysiological impairment, for further studies to examine this assumption.

The limitation of this study was that the finding of sensory axonal loss was not examined if it is more in the dominant hand, as the dominant hand could have more increased pressure and more sensory cortical representation which are the two suggested mechanisms for this abnormality.

\section{Conclusion}

There is some electrophysiological evidence of pressure on the adjacent ulnar nerve fibers in patients with minimal to moderate CTS, and the abnormality was greater in moderate and extreme grades. This may argue in favor of the potential effect of CTS on the ulnar nerve given changes in the magnitude of the sensory ulnar nerves and did not suggest axonal degeneration of the ulnar nerve.

\section{Abbreviations}

CTS: Carpal tunnel syndrome; D2: Digit 2; D4: Digit 4; D5: Digit 5; DL: Distal latency; GC: Guyon's canal; GOTHI: General Organization for Teaching Hospitals and Institutes; MNCS: Motor nerve conduction studies; NCS: Nerve conduction study; SCS: Sensory conduction study; SD: Standard deviation

\section{Acknowledgements}

Not applicable

\section{Authors' contributions}

Selection of patients, clinical examination, and electrodiagnostic studies were done by Dr. AOE, and Dr. SSA in Mataria Teaching Hospital and Dr. RAI in Ain Shams Hospital. Statistical analysis and manuscript writing and editing were done by Dr. AOE and Dr. RAI. All authors have read and approved the manuscript.

\section{Funding}

The study had no funding from any resource.

\section{Availability of data and materials}

All data generalized and/or analyzed during the current study are available from the authors upon reasonable request.

\section{Ethics approval and consent to participate}

This study was conducted after the approval of the ethics committee of the General Organization for Teaching Hospitals and Institutes (GOTHI), with reference number HM00122. All patients in this study gave written informed consent to participate in this research.

\section{Consent for publication}

Not applicable

\section{Competing interests}

There are no competing interest.

\section{Author details}

${ }^{1}$ Physical Medicine, Rheumatology and Rehabilitation Department, Al-Mataria Teaching Hospital, Cairo, Egypt. ²Physical Medicine, Rheumatology and Rehabilitation Department, National Institute For Neuro-Motor System, Giza, Egypt. ${ }^{3}$ Physical Medicine, Rheumatology and Rehabilitation Department, Faculty of Medicine, Ain Shams University, Cairo, Egypt.

Received: 4 April 2020 Accepted: 23 April 2020

Published online: 09 June 2020

\section{References}

1. Ginanneschi F, Mondelli M, Cioncoloni D, Rossi A (2018) Impact of carpal tunnel syndrome on ulnar nerve at wrist: systematic review. J Electromyogr Kinesiol 40:32-38

2. Maroukis BL, Ogawa T, Rehim SA, Chung K (2015) Guyon canal: the evolution of clinical anatomy. J Hand Surg Am 40:560-565

3. Sedal L, MC Leod JC, Walsh JC (1973) Ulnar nerve lesions associated with carpal tunnel syndrome. J Neurol Neurosurg Psychiatry 36:118-123

4. Cassvan A, Rosenberg A, Rivera LF (1986) Ulnar nerve involvement in carpal tunnel syndrome. Arch Phys Med Rehabil 67:290-292

5. Gozke E, Dortcan N, Kocer A, Cetinkaya M, Akyuz G, Us O (2003) Ulnar nerve entrapment at wrist associated with carpal tunnel syndrome. Neurophysiol Clin 33:219-222

6. Ginanneschi F, Milani P, Mondelli M, Dominici F, Biasella A, Rossi A (2008) Ulnar sensory nerve impairment at the wrist in carpal tunnel syndrome. Muscle Nerve 37:183-189

7. Yemisci OU, Yalbuzdag SA, Cosar SN, Oztop P, Karatas M (2011) Ulnar nerve conduction abnormalities in carpal tunnel syndrome. Muscle Nerve 44:352357

8. Azmy RM, Labib AA, Elkholy SH (2013) Axonal degeneration of the ulnar nerve secondary to carpal tunnel syndrome: fact or fiction? Neural Regen Res 8:1418-1422

9. Eom Yl, Choi MH, Kim YK, Joo IS (2015) Sonographic findings in the ulnar nerve according to the electrophysiologic stage of carpal tunnel syndrome. J Ultrasound Med 34:1027-1034

10. Zhang J, Liu N, Wang YW, Zhang ZC, Zheng LN, Zhu J (2015) Evaluation of the function status of the ulnar nerve in carpal tunnel syndrome. Genet Mol Res 14:3680-3686

11. Sakly G, Affes Z, Dhia SB, Trabelsi A, Cheikh RB, Gammoudi N, Dogui M (2016) The impact of carpal tunnel syndrome on ulnar nerve: an electroclinical study. J Neurol Neurosci 7-5:153 
12. Kose Ozlece H, Huseyinoglu N, Gok M, llik F (2016) Ultrasonographic and electrophysiological evaluation of the ulnar nerve in patients diagnosed with carpal tunnel syndrome. J Clin Neurophysiol 33:464-468

13. Selek Ö, Alemdar M (2017) Are the sensory fibers of the ulnar nerve affected in carpal tunnel syndrome? J Clin Neurophysiol 34:502-507

14. Ablove RH, Peimer CA, Diao E, Oliverio R, Kuhn JP (1994) Morphologic changes following endoscopic and two-portal subcutaneous carpal tunnel release. J Hand Surg [Am] 19:821-826

15. Ablove RH, Moy OJ, Peimer CA, Wheeler DR, Diao E (1996) Pressure changes in Guyon's canal after carpal tunnel release. J Hand Surg Br 21:664-665

16. Richman JA, Gelberman RH, Rydevik BL, Hajek PC, Braun RM, Gylys-Morin VM (1989) Carpal tunnel syndrome: morphologic changes after release of transverse carpal ligament. J Hand Surg [Am] 14:852-857

17. Ginanneschi F, Milani P, Rossi A (2008) Anomalies of ulnar nerve conduction in different carpal tunnel syndrome stages. Muscle Nerve 37:1155-1160

18. Chang MH, Lee YC, Hsieh PF (2008) The role of forearm mixed nerve conduction study in the evaluation of proximal conduction slowing in carpal tunnel syndrome. Clin Neurophysiol 119:2800-2803

19. Preston D, Shapiro B (eds) (2013) Electromyography and neuromuscular disorders: clinical-electrophysiologic correlation, 3rd edn. Elsevier, Pennsylvania

20. Bland JD (2000) A neurophysiological grading scale for carpal tunnel syndrome. Muscle Nerve 23:1280-1283

21. Ginanneschi F, Dominici F, Milani P, Biasella A, Rossi A (2007) Evidence of altered motor axon properties of the ulnar nerve in carpal tunnel syndrome. Clin Neurophysiol 118:1569-1576

22. Lin CS, Kuwabara S, Cappelen-Smith C, Burke D (2002) Responses of human sensory and motor axons to the release of ischemia and to hyperpolarizing currents. J Physiol 541:1025-1039

23. Mondelli M, Ginanneschi F, Rossi A (2009) Evidence of improvement in distal conduction of ulnar nerve sensory fibers after carpal tunnel release. Neurosurgery 65:696-700

24. Saba EK, El-Tawab SS (2014) Ulnar nerve changes associated with carpal tunnel syndrome not affecting median versus ulnar comparative studies. World J Med Sci 11:600-608

25. Moghtaderi A, Ghafarpoor M (2009) The dilemma of ulnar nerve entrapment at wrist in carpal tunnel syndrome. Clin Neurol Neurosurg 111: $151-155$

26. Tamburin S, Cacciatori C, Praitano ML, Marani S, Zanette G (2009) Ulnar nerve impairment at the wrist does not contribute to extramedian sensory symptoms in carpal tunnel syndrome. Clin Neurophysiol 120:1687-1692

27. Zanette G, Marani S, Tamburin S (2006) Extra-median spread of sensory symptoms in carpal tunnel syndrome suggests the presence of pain-related mechanisms. Pain 122:264-270

28. Tecchio F, Padua L, Aprile I, Rossini PM (2002) Carpal tunnel syndrome modifies sensory hand cortical somatotopy: a MEG study. Hum Brain Mapp 17:28-36

29. Fernández-de-las-Peñas $C$, de la Llave-Rincón Al, Fernández-Carnero J, Cuadrado ML, Arendt-Nielsen L, Pareja JA (2009) Bilateral widespread mechanical pain sensitivity in carpal tunnel syndrome: evidence of central processing in unilateral neuropathy. Brain 132:1472-1479

\section{Publisher's Note}

Springer Nature remains neutral with regard to jurisdictional claims in published maps and institutional affiliations.

\section{Submit your manuscript to a SpringerOpen ${ }^{\circ}$ journal and benefit from:}

- Convenient online submission

- Rigorous peer review

- Open access: articles freely available online

- High visibility within the field

- Retaining the copyright to your article

Submit your next manuscript at $\boldsymbol{\nabla}$ springeropen.com 